\title{
Assessing The Value Of Certification Preparation Programs In Higher Education
}

\author{
Vincent S. Daniels, Nova Southeastern University, USA
}

\begin{abstract}
The purpose of this article is to begin an exploration into the value of certification preparation programs in high skills lifelong learning, specifically in the field of business and management. This segment of lifelong learning is often referred to as executive and professional education (EPE).

As professions and skills are made obsolete in the knowledge economy the need for continued high level lifelong learning becomes increasing important to the sustainability and viability of local, regional, state and national economies.

This research paper focuses on programs that prepare participants for nationally and internationally recognized certifications. Additionally the research addresses issues relating to the motivation of participants to enroll in EPE programs.
\end{abstract}

Keywords: adult education; executive education; non-credit courses; student motivation

\section{INTRODUCTION}

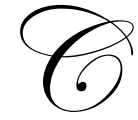

urrent economic thinking in developed western countries places knowledge-led industries in the forefront of economic development (Gore, 1999). Taking this concept as a starting point, the paper will seek to examine the value of an active education system delivering programs to prepare individuals for high skills business certifications required to support the growth of knowledge-led economic development. To support the concept that education underpins the development of local knowledge led industries (Drucker, 1999; OECD, 1999; Wood, 2003), a delivery system is required.

To support this inquiry, two research questions were developed:

1. Why are certification preparation programs an important element of EPE?

2. What motivates participants to take part in certification preparation programs in EPE? A survey was administered to participants in EPE to determine reasons for their participation in both general EPE programs and certification preparation programs.

\section{Executive And Professional Education (EPE)}

As we move more strongly into the knowledge based economy, and as knowledge creation expands exponentially, the need for a continued updating of knowledge and skills in the working community becomes evident.

The leadership and management roles of the future require additional and continually evolving skills and knowledge. EPE consists of two primary areas - soft and functional skills. Soft skills are skills, such as leadership and communication, are essential to success. With a constant evolution of new jobs in the knowledge-based economy (Kerka, 1993), leaders and professionals are required to be continually updating and refining these essential skills. Technical or functional area skills are acquired either at work or through formal training and 
education. Soft skills, or social behavioral skills, must be learned through understanding and practice (Lewis, 2007). Functional skills may typically be acquired in a logical and systematic way, while management and interpersonal skills must be acquired through training, coaching and practice (Douglas, 2002; Singh, 2005). The functional knowledge area emphasizes advanced learning in areas such as finance, management, business technology and marketing, to name a few.

In one's career, new knowledge and technology are constantly expanding. What one learns in the university degree programs is outdated quickly and additional knowledge must be continually added in order to remain current and effective (OECD, 1999, p. 4). Nationally and internationally recognized certification programs contribute to this requirement of continual learning and will be discussed in detail.

This article will also examine the history and development of EPE and the role of the university in this particular aspect of higher education. Specifically, the importance of certification programs will be analyzed. Critical to the understanding of EPE is knowledge of why people take part in this form of education.

\section{History Of Knowledge Transfer}

An understanding of the history of studies into knowledge and its transfer serves as a starting point in understanding how knowledge has been transferred throughout history and how this has changed in substantial ways up to the present.

In the beginning of civilization, the transition from hunter gatherer to a more agrarian society involved the development of skills related to farming. These skills were transmitted by the methods of the time; namely, orally and through practice. Such methods held well into the middle ages when most of the population was employed in some form of agriculture.

As cities grew and developed, craft groups evolved; for example, masons, leather workers, etc. A significant development in this area was the formation of craft guilds. A guild had many responsibilities, but high among these was the training of apprentices in the skill of the craft. The formation of guilds also enabled the transmission of skills over distances and through generations. The guilds, in addition to teaching skills, also played the equally important roles of managing quality within the crafts and prescribing and regulating standards (Andromeda, 1997).

\section{Tacit And Explicit Knowledge}

Much tacit knowledge is impossible to be made explicit. We may know how to do something, but are incapable of describing it in words or pictures. On the other hand, "Tacit knowledge comprises a range of conceptual and sensory information and images that can be brought to bear in an attempt to make sense of something" (Smith, 2003, p. 2).

Tacit knowledge has been defined as "The process by which knowledge or information evolves and spreads through the economy, which involves changing its nature between tacit and codified forms" (Cowan \& Foray, 1997, p. 1). Michael Polanyi (1966, p. 4) in The Tacit Dimension states, "we can know more than we can tell" in order to illustrate the concept that much more can be known intrinsically than can be converted into explicit information of data. Throughout history, tacit knowledge has been passed from mentor to protégé without the benefit of converting the knowledge into a codified format. Tacit knowledge is much more difficult to codify than information, but progress continues in this area.

Another important distinction exists between what we know and what we know how to do. We can learn (acquire knowledge) in two ways: 1) We learn when our senses receive input, as Aristotle theorized, and 2) We learn by doing through the application of knowledge we already have, or, more intensely and indelibly, through the process of applying latent knowledge. Once knowledge has been applied through doing and we have thoroughly internalized the use of the knowledge, it becomes a skill (Brown et al, 2001). Most skills are developed "on the job," through experimentation or under the tutelage of others. When analyzing the growth of specialized 
certifications in today's world, it becomes clear that an important function of a certifying organization, in addition to certifying that a practitioner has the necessary competencies to meet a prescribed standard, is to transform or translate tacit knowledge into explicit knowledge. The transformation of tacit knowledge to explicit knowledge is also a process of distillation in which the most "relevant" knowledge and the "best practices" are translated into a "body of knowledge." A body of knowledge, then, is incomplete in that it does not represent a field or subject in its entirety but rather those elements of the field that have remained in tact after the certifying agency has applied its process of distillation to the field. Nonetheless, codification of tacit knowledge is a major and irreversible step in the direction of explicit knowledge distribution.

According to Grant (2000, p27), if knowledge exists in two principal forms - explicit and tacit - and at two major levels - the individual and the organization - then there are significant benefits to the organization in shifting its primary knowledge base from individually held tacit knowledge to organization-wide explicit knowledge.

The critical difference between tacit and explicit knowledge relates to how easy or difficult it is to codify or express the knowledge in terms which enable it to be understood by a broad audience. If knowledge can be codified in this way, then it can be made explicit and thus readily transferable (Burton-Jones, 1999).

\section{Functional And Soft Skills}

EPE falls into two categories. The first category can be called "functional" education. Functional programs are those which are primarily concerned with knowledge rather than skills. The second EPE category might be called the "social-behavioral skills" area, or "soft skills". These programs are generally related to so-called soft skills development. These skill areas might address communication or leadership skills. While knowledge is required for these skills to be developed, the primarily goal of these programs is to assist participants in developing skills that they can bring back to the workplace.

Professionals tend to require EPE education as they may be owners of their own practices or involved in management of their organization, be it a law firm or hospital. The book, The Yale Physician's Guide to Business (Rimar, 2001), covers this requirement for physicians in detail. The book espouses MBAtype education for physicians. An MBA provides a wide coverage of functional areas of business and management. This prepares a professional to be a complete business team as an individual (Daniels, 2005).

Another group of programs that fall predominantly into the functional classification are programs that lead to, or are required for, various certifications. These programs are special because the content and outcomes are generally dictated by a national or international body that awards the certification. As discussed previously in this article, these programs are increasingly demanded. These programs include topics such as:

$$
\begin{array}{ll}
- & \text { Certified Management Accountant }\left(\mathrm{CMA}^{\circledR}\right) \text { Certification Program } \\
\text { - } & \text { Certified Treasury Professional }\left(\mathrm{CTP}^{\circledR}\right) \text { Certification Program } \\
\text { - } & \text { Human Resource Professional }\left(\mathrm{PHR}^{\mathrm{S}} \mathrm{SHR}^{\circledR}\right) \text { Certification Program } \\
\text { - } & \text { Projified Purchasing Manager }\left(\mathrm{CPM}^{\circledR}\right) \text { Certification Program } \\
& \text { Project Management }\left(\mathrm{PMP}^{\circledR}\right) \text { Preparation Program. }
\end{array}
$$

More relevant to EPE is a body of knowledge, such as the Project Management Body of Knowledge,

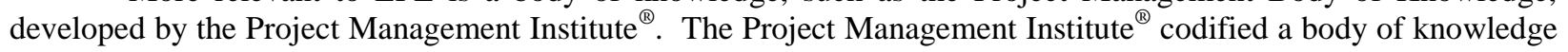
published as the Project Management Body of Knowledge (PMBOK). This codification takes many best practices, most of which were initially tacit, and codifies the knowledge to make it available to a large audience. This is not to say that the PMBOK is the only approach to project management, as many other books have been written, but the PMBOK forms the basis for the examination to become certified as a Project Management Professional ${ }^{\circledR}$, or PMP ${ }^{\circledR}$. Only with such a codification can a program that develops project managers and prepares them for the certification exam be taught effectively through EPE.

Similarly, other professional certification organizations, which are nationally or internationally recognized, have developed programs or knowledge bodies which serve as the basis for their certification examinations. Some 
of these are the Society for Human Resource Management ${ }^{\circledR}$ with the Professional in Human Resources (PHR ${ }^{\circledR}$ ) and Senior Professional in Human Resources $\left(\mathrm{SPHR}^{\circledR}\right)$ certifications, the Institute of Supply Management with the Certified Purchasing Management $\left(\mathrm{CPM}^{\circledR}\right)$ certification, the Institute of Management Accountants with the Certified Management Accountant $\left(\mathrm{CMA}^{\circledR}\right)$, and numerous others.

\section{Continuing Education}

Continuing education falls into several categories, many of which are easily tracked and measured and which could consequently be included as indicators for measuring learning and knowledge. The first category of continuing education is the completion of undergraduate and graduate degrees. Generally speaking, undergraduate and graduate degrees are considered a part of the number of years of education, but increasingly, people are not seeking undergraduate degrees immediately following high school or graduate degrees immediately following college (Stokes, 2006). More and more people are returning to formal education after a long hiatus.

The second category of continuing education is also experiencing rapid growth - the area of widely recognized certificate programs. Generally this category is not affiliated with an institute of higher learning. "Professionals themselves set standards since they have the knowledge necessary to do so" (Bailey \& Merritt, 1995). These certifications usually fall under a specialty organization such as the Project Management Institute (PMI), the Association for Financial Professionals (AFP), or the Institute for Supply Management (ISM). As an example of the growth in certification acceptance, the AFP website asserts "demand for the AFP certification has grown from the almost 1,000 examinees in 1986 to the over 2,500 in 2005. These numbers reflect the demands of the treasury workplace for a knowledgeable, skilled employee. During the past 20 years, over 17,000 professionals have earned their certification" (http://www.afponline.org). According to the ISM website, the number of practitioners awarded the Certified Purchasing Manager (CPM®) designation has grown from 36,893 in fiscal year 2000-2001 to 42,266 in fiscal year 2003-2004, an increase of nearly 15\% (http://www.napm.org). Not only is the awarding of these certifications easy to track and to include as a valuable indicator but, as will be seen in Table 1, Industry Based Credentials, of which certifications are a part, are also highly valued by employers.

The National Skills Certification Board is charged with developing, jointly with industry, education and labor, a system of "skill certification that enhances career advancement and job security, and allowing students and entry-level workers to identify the skill levels necessary for high wage jobs." (Zemsky et al.) Also an important element of skill certifications is portability. "Graduates would also have better access to a national labor market (if the certification is recognized nationally), thus promoting their geographic and occupational mobility." (Bailey \& Merritt, 1995)

Table 1: Employers' Rating Of The Importance Of Various Applicant Characteristics For Making Hiring Decisions: 1997 Applicant Characteristic Average Score

\begin{tabular}{|l|l|}
\hline Attitude & 4.60 \\
\hline Communication Skills & 4.07 \\
\hline Previous Job Performance & 4.04 \\
\hline Full-Time Work Experience & 3.75 \\
\hline Industry Based Credentials & 3.18 \\
\hline Education Level & 2.89 \\
\hline After-school or Summer Work & 2.62 \\
\hline Technical Course Work & 2.52 \\
\hline Academic Performance & 2.47 \\
\hline Extracurricular Activities & 2.31 \\
\hline General Course Work & \\
\hline School Reputation & 2.30 \\
\hline Source: Danis Shapi and & 2.00 \\
\hline
\end{tabular}

Source: Daniel Shapiro and Margaret Goertz, "Connecting Work and School: Findings from the 1997 National Employer Survey," Unpublished paper presented at the annual meeting of the American Educational Research Association, San Diego, California, April 15, 1998 
The third category of life-long learning is vendor-specific certifications. Technology companies, like Microsoft, Cisco, and IBM, offer various certifications (Koziniec \& Dixon, 2001) which are highly sought after by job seekers and free-lance workers. Many jobs require these certifications before even considering applicants. Training for these certifications is also easily tracked and is offered through traditional modes as well as through specialty training centers and electronic media.

Industry-based certifications offer a pathway to career opportunities (Adelman, 2000). They offer an external validation of quality (Everett et al).

\section{Defining "High Skills"}

The term "high skills" is used extensively in the literature, frequently without a definition. We have seen that a knowledge-based economy has some ability to be measured and the level of skills is a component of this measurement. In High Skills by Phillip Brown, Andy Green and Hugh Lauder, there is also no absolute definition of high skills. The authors mention in a footnote (2001, p. 54) that a high skills economy has a preponderance of skills, which are at the "professional, managerial, technical" levels.

While unskilled labor is defined as "anyone educated to the secondary level only, with no higher level or specific skills qualification" (Bassanini, 2003, p. 1), high skills is largely left undefined. Brown admits that "skill" is a term very difficult to define. "Skills is variously defined as the expertise, ability, or competence to undertake specific activities often acquired through formal instruction or work experience" (Brown, et. al., 2001, p. 23). As with other commodities, the highly skilled worker is affected by supply and demand. In a knowledge-based economy, according to Vickery and Wurzburg, "There is a general increase in educational attainment on the supply side. On the demand side, there is a shift towards high-skill, white-collar occupations (managers, professional, staff)... Sectors and occupations that are growing the most are those in which standards of attainment have risen most, in, for example, rapidly growing business and financial services and high-tech manufacturing" (Vickery \& Wurzburg, 1996, p. 21).

Although "high skills" is not adequately defined in the literature, in the area of business and management education, EPE, it is more easily definable. Drawing on the research included in this article and many years of personal experience in delivering EPE, a definition is possible.

High skills EPE consists of educational and learning programs offered to management-level employees and above. Basic courses, such as time management, business writing and Microsoft ${ }^{\circledR}$ Office software usage, do not fit in the classification of high skills. These courses provide participants with basic office and self-management knowledge and skills. High skills commence only beyond the scope of these basic skills programs.

In the areas of skills in the EPE definition are programs for managers, executives and professionals. These may be courses targeted toward officers and managers in business corporations, not-for-profit organizations, and government bodies. Also included in this definition are professionals operating in the high skills arena, requiring advanced education and, in most cases, professional certification. This group includes such professionals as lawyers, accountants, physicians and educators. In most cases, activity in these professions requires continuing education relative to the profession, but may include business and management education.

\section{Why Do People Participate In EPE-Type Education?}

Participants take part in EPE for a variety of reasons. A survey was conducted by the Hudson Institute of Entrepreneurship and Executive Education of Nova Southeastern University in Fort Lauderdale, Florida, to determine the reasons for participation. The data were collected from April through June, 2008 (Daniels \& Preziosi, 2009). 
The primary reasons for participation are:

- $\quad$ to increase skills or knowledge in a current career or profession

- $\quad$ to prepare for transition to a different career or profession

- $\quad$ to move into a position of management or leadership

- $\quad$ to advance to a higher level management or leadership position

- $\quad$ to be recognized as an expert in a career or profession

- to increase skills or knowledge in a current career or profession

As detailed in this article, the rapid advancement of knowledge in various careers and professions obligates practitioners to be continually updating their skills and knowledge. EPE can supply the updated knowledge needed to develop cutting edge skills.

\section{To Prepare For Transition To A Different Career Or Profession}

The rapid changes in technology and productivity have caused the demise of numerous careers, professions and even business enterprises. Secretaries and typists serve as very obvious examples. As industries have moved from labor-intensive to technology-intensive, such as the automotive industry's rapid move to robotic manufacturing, numerous job titles have been eliminated. There is a need for many knowledge workers and many employees in these obliterated careers have found a need to move into a new career, very often a knowledgeintensive career. These career changes require new knowledge and skill sets. EPE is in the position to provide much of the education needed to assist these displaced workers in entering a new profession.

Even without the trauma of loss of a career, numerous participants take advantage of EPE in order to enter into a new career that will offer them better opportunities for advancement, satisfaction and rewards.

\section{To Move Into A Position Of Management Or Leadership}

As people advance in their careers and professions, many find that they wish to move into management and leadership positions in their organization. These may be sales people who want to be sales managers, police officers who get promoted to sergeant, or medical doctors who are appointed to a board or given administrative responsibilities in a hospital. In all cases, the skill sets required in the new management or leadership position are quite different from the skills that were required to be successful in the non-managerial role.

\section{To Advance to A Higher Level Management or Leadership Position}

Managers in organizations often have the opportunity to advance to higher levels of responsibility. Managers may have an adequate knowledge of their particular functional areas, but to move from managers to officers of the organization or from officers to board members will require a broader knowledge and additional socio-behavioral (soft) skills. An officer of an organization often has to understand how various functional areas interrelate and affect outcomes in other areas of the organization and in the organization as a whole. Board members must have an understanding of the relationship of the organization with the outside stakeholders. Positions in senior and executive management require additional knowledge and skills that are often available through the EPE of a university.

\section{To Be Recognized As An Expert In A Career Or Profession}

Another area in which EPE can play a significant role is in preparing participants for professional certifications. As described elsewhere in this article, there is an increasing demand for individuals who can exhibit competence in a particular specialization through becoming certified by a recognized certifying organization. Some certifications previously listed are the Certified Treasury Professional, Certified Management Accountant, Certified Public Accountant, Project Management Professional, Certified Purchasing Manager and Professional in Human Resources, to name a few. 


\section{Survey Utilizing Questionnaire}

The framework derived from the initial case study was used to establish numerous questions in the survey. The primary purpose of the survey is to address the questions: "What are the major components of EPE?" and "What motivates participants to take part in EPE?"

\section{Surveys}

A survey is a positivistic methodology whereby a sample of subjects is drawn from a population and studied to make inferences about the population (Hussey \& Hussey, 1997). As the population to be studied is participants in EPE programs, it was decided to design a questionnaire to be utilized in EPE classes. The Hudson Institute of Entrepreneurship and Executive Education (HIEEE) of Nova Southeastern University in Fort Lauderdale, Florida, delivers EPE programs, both open enrolment and in-house, for particular companies and organizations. The HIEEE agreed to assess participants in EPE programs utilizing the questionnaire designed by the researcher. The data were collected from April through June, 2008.

The items included in the questionnaire were developed based on experience of the researcher in administering EPE programs (Daniels, 2009; Daniels \& Preziosi, 2010), as well as through the literature (Burke, 2006; Jenkins, et al, 2002). Through informal interviews with participants, both prior to and immediately following the EPE programs, the researcher was able to identify motivators of participants. This list of possible motivators was then reviewed by several faculty members and instructors who deliver EPE programs for their input and was included in the questionnaire as follows:

Please rank the following statements as to their influence in motivating you to take part in this continuing education program:

1. Increase skills and knowledge in my current career/profession

2. Prepare for transition to a different career/profession

3. Enhance skills and knowledge to advance in current career/profession

4. Move into a management/leadership position

5. Be recognized as an expert in my current career/profession

6. Other. Please explain.

Participants were asked to rate each of these on a scale of 0 through 5 as follows:

0. $\quad$ Not applicable

1. Not important in motivating me to take part in this program

2. Low importance, but somewhat affected my decision to enroll in this program

3. Important. This knowledge or these skills are important to my future success

4. Very important. Not having these skills or this knowledge will be detrimental to my career development.

5. Highest importance. Absolutely essential for continued success

A total of 99 participants took part in this survey.

As with any questions developed by involved individuals, a certain amount of subjectivity can influence the question selection. It is believed that the experience of the director, coupled with the faculty/instructor review, has made the question selection as objective as possible.

A Likert-style scale was utilized in collecting and evaluating responses of the participants. Respondents' attitudes are measured from lowest (1) to highest (5). A possible selection of "Not applicable" (0) is also included to be utilized by the respondent when applicable (Berg, 1998; Rea \& Parker, 1997). The Likert scale was accepted by the researcher as an adequate method to evaluate participants' attitudes toward importance of the motivations indicated in the questions. A Likert scale offers an acceptable method of measuring the relative importance of goals 
(Maurer \& Pierce, 1998). While the Likert scale has been challenged as having potential differences in understanding among cultures (Lee, Jones, Mineyama \& Zhang, 2002), for the purpose of this research where respondents were reasonably culturally homogeneous, it was determined by the researcher to be an acceptable measuring device.

The 99 participants taking part in the survey completed nine different EPE programs. All participants agreed to take part in this anonymous survey, which was administered at the conclusion of the EPE program in which they participated.

\section{Gain Recognition}

Recognition was considered important or greater by $80 \%$ of participants. The HIEEE prints certificates of completion, suitable for framing for each participant in each program. The positive response to this question (Figure 1) accentuates the desire for professional recognition.

These responses support the concepts presented in this article about the importance of certification preparation programs as an integral part of the EPE offering.

Figure 1: Recognition

\begin{tabular}{|l|c|}
\hline Be Recognized As An Expert In My Current Career/Profession & 6 \\
\hline 0 Not applicable & 6 \\
\hline 1 Not important in motivating me to take part in this program & 7 \\
\hline 2 Low importance, but somewhat affected my decision to enroll in this program & 20 \\
\hline 3 Important. This knowledge, or these skills are important to my future success & 14 \\
\hline 4 Very important. Not having these skills or this knowledge will be detrimental to my career development. & 46 \\
\hline 5 Highest importance. Absolutely essential for continued success & \\
\hline
\end{tabular}

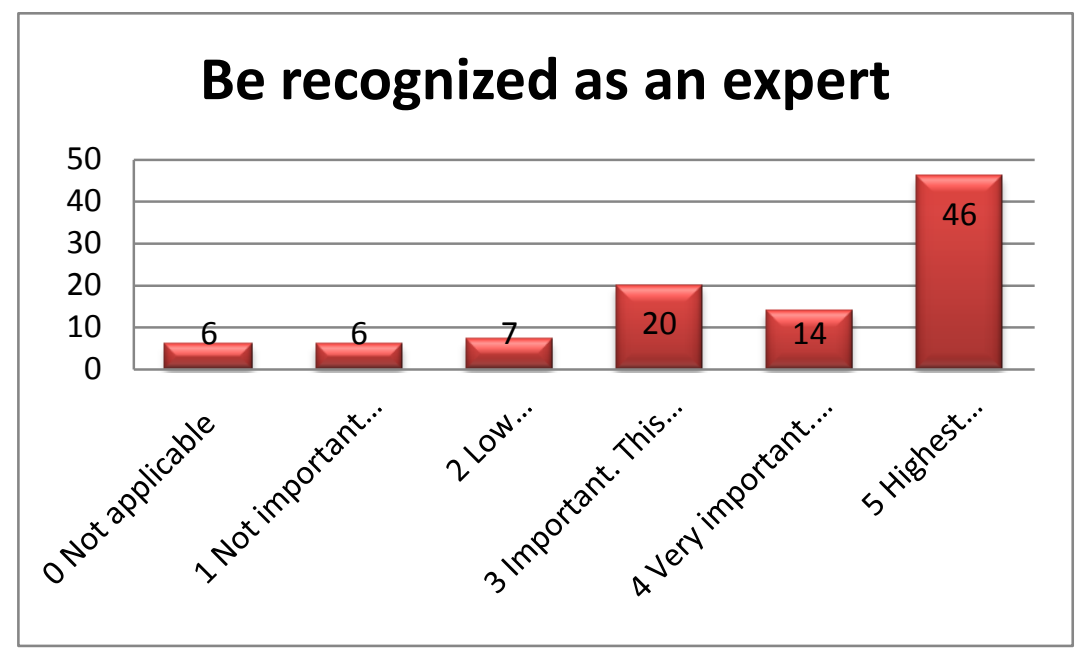

\section{CONCLUSION: COMMITMENT TO CERTIFICATION TRAINING}

High skills certifications are a modern example of the guild process at work. These certifications establish a measurement of knowledge and attest to the skill level of the certified parties. The certification bodies typically devote much time and effort to converting intrinsic knowledge and skills to best practices and explicit, transferable knowledge. Universities are the traditional institutions that take part in the transfer of knowledge. While research 
and traditional degrees are at the top of the list of deliverables from universities, certification preparation programs would fit very well into the educational mix.

Future research can inquire into the effects of various high skills certifications on national economies, and whether measurement of high skills certifications in an economy can function as an indicator of the knowledge value of these economies.

\section{AUTHOR INFORMATION}

Dr. Vincent S. Daniels (Vince) is Assistant Professor of Management at the H. Wayne Huizenga School of Business and Entrepreneurship at Nova Southeastern University. He teaches in strategy, sales management and negotiating, and delivers training to corporations in sales and management. In 1973, Vince Graduated with honors from the University of Tampa. He then attended the Thunderbird, American Graduate School of International Management and received an MBA in International Management in 1974, as the Barton Kyle Yount honor graduate. He was also honored as Entrepreneur of the Year in 1988 by Thunderbird. Vince has been listed in Who's Who in the World and Who's Who in the Southeast. He was the founding director of the International MBA program at Florida International University where he taught classes in entrepreneurship, marketing and sales. In 2004 he joined Nova Southeastern University as Executive Director of Executive Education, moving to a faculty position in 2010. Vince is the author of many articles on sales and strategy, and one book, International Sales - How to Excel in Global Selling.

\section{REFERENCES}

1. Adelman, C. (2000). A parallel postsecondary universe: The certification system in information technology. U.S. Department of Education: Office of Educational Research and Improvement. Anderla, G. (1973). A Challenge for Governments and Society, OECD Observer

2. Bailey, T. \& Merritt, D. (1995). Making Sense of Industry-Based Skill Standards, National Center for Research in Vocational Education

3. $\quad$ Andromeda (1997), Atlas of World History, Andromeda Oxford Ltd.

4. assanini, A. (2003). Solving the training divide. OECD Observer, No. 240/241.

5. Berg, L. (1998). Qualitative research methods for the social sciences, Allyn \& Bacon

6. Brown, P., Green, A. \& Lauder, H. (2001). High Skills. Oxford University Press.

7. Burke, P. J. (2006) Men accessing education: gendered aspirations, British Educational Research Journal, 32: $5,719-733$

8. Burton-Jones, A. (1999). Knowledge Capitalism. Oxford University Press.

9. Cowan, R. and Foray, D. (1997). The Economics of Codification and the Diffusion of Knowledge. http://icc.oxfordjournals.org/cgi/content/abstract/6/3/595.

10. Daniels, V. (2005). The Global Chameleon, DISC

11. Daniels, V. \& Preziosi, R. (2010) Motivational Patterns Of Enrollees in University-Based Executive and Professional Education Courses, American Journal of Business Education 3(8)

12. Douglas, M. (2002). Why 'soft skills' are an essential part of hard world of business. The British Journal of Administrative Management, (34), 34-35.

13. Everett, J., Gershwin, M., Hayes, H., Jacobs,, J., \& Mundhenk, R. (2002). How Should “Quality" Technical Education and Training be Defined?, Office of Vocational and Adult Education, U.S. Department of Education

14. Grant, R., (2000). Knowledge horizons: the present and the promise of knowledge management. Butterworth-Heinemann.

15. Huber, G., (1984). The Nature and Design of Post-Industrial Organizations. Management Science, 30(8), 928-951.

16. Hussey, J., Hussey, R., (1997). Business Research: A Practical Guide for Undergraduate and Postgraduate Students. Palgrave.

17. Jenkins, A., Vignoles, A., Wolf, A., \& Galindo-Rueda, F. (2002). The Determinants and Effects of Lifelong Learning. Centre for the Economics of Education 
18. Kerka, S. (1993). Career Education for a Global Economy. Clearinghouse on Adult Career and Vocational Education.

19. Koziniec, T. \& Dixon, M (2002). ICT Industry Certification: Integration Issues for Post-Secondary Educational Institutions, Informing Science, June 2002.

20. Lee, W., Jones, P., Mineyana, Y. \& Zhang, X (2002), Cultural differences in responses to a Likert scale, Research in Nursing and Health, 25(4) pp 295-306.

21. Lewis, A. (2007). Attention to Soft Skills. Tech Directions, 66(6), 6.

22. Maurer, J. \& Pierce, H. (1998) A comparison of Likert scale and traditional measures of self-efficacy, Journal of Applied Psychology, 83(2), pp 324-329

23. Organization for Economic Co-Operation and Development (OECD). (1996). The Knowledge-Based Economy. Organization for Economic Co-operation and Development. Paris.

24. Polanyi, M. (1966). The Tacit Dimension. Doubleday

25. Rea, L \& Parker, R. (1997). Designing and Conducting Survey Research, Jossey-Bass

26. Rimar, S. (2001). The Yale Physician's Guide to Business. Wiley

27. Ryan, D. P. (1988). Papyrus. The Biblical Archaeologist, 51(3), 132-140.

28. Singh, R. (2005). The Missing "Soft Skills" for Project Controls. AACE International Transactions, DE11DE12.

29. Smith, A. (1776). An Inquiry into the Nature and Causes of the Wealth of Nations

30. Smith, M.K. (2003). Michael Polanyi and tacit knowledge. the encyclopedia of informal education, www.infed.org/thinkers/polanyi.htm. Last updated: June 04, 2005.

31. Stokes, P.J. (2006). Hidden in Plain Sight: Adult Learners Forge a New Tradition in Higher Education. The Secretary of Education's Commission on the Future of Higher Education. Issue Paper.

32. Vickery, G., and Wurzburg, G. (1996). Flexible Firms, Skills and Employment. OECD Observer, No. 202.

33. Zemsky, R., Shapiro, D., Iannozzi, M., Capelli, P. \& Bailey, T. (1998). The Transition From Initial Education To Working Life In The United States Of America. Organisation for Economic Co-operation and Development (OECD) 